\title{
Strategic Environmental Policy and Environmental Tariffs
}

\author{
Yuqing Xing \\ International University of Japan
}

\begin{abstract}
This paper uses a three-stage game to analyze how environmental tariffs affect the strategic behavior of a government in designing environmental policy. The game is based on an international duopoly model with detrimental externality in production and asymmetric environmental policies between two countries. It shows that the welfare effect of the foreign country's strategic environmental policy on the home country is ambiguous. In the circumstance that the home country would be worse off due to the lenient environmental policy of the foreign country, there exists an optimal environmental tariff. If the home country imposes the optimal tariff on the pollution-intensive imports, any deviation from the first best environmental policy by the foreign country would make the home country better off. In addition, the implementation of the environmental tariff would mitigate the motivation of the foreign country to pursue strategic environmental policy, and drive the lenient environmental standard toward the efficient level. The theoretical results imply that, in an open economy with non-harmonized environmental standards, imposing environmental tariffs on imports from the countries with lax environmental regulations would correct the adverse welfare effect, and more importantly induce the upward harmonization on environmental policy across countries.
\end{abstract}

- JEL classification: Q28, Q38

- Keywords: Environmental Regulations, Imperfect Competition, Tariffs

\footnotetext{
*Corresponding address: Yuqing Xing, International Development Program, Graduate School of International Relations, International University of Japan, 777 Kokusia-Cho, Minami Uonuma Shi, Niigata-ken, 9494-7277, Japan. Phone: 81-(25)-779-1464, Fax: 81-(25)-779-1187, E-mail: xing@iuj.ac.jp. (c)2006-Center for International Economics, Sejong Institution, All Rights Reserved.
} 


\section{Introduction}

A major objection of environmentalists against free trade has been the concern that international competition would undermine environmental standards and induce the downward harmonization of environmental policy among nations. Environmentalists voiced their concern violently during the World Trade Organization summits from Seattle to Cancun. Some economists, on the other hand, often ignore the influence of competition on the stringency of environmental regulations and ascribe the lax environmental regulations of a country to natural factors such as assimilative capacity, social preferences and economic development (Bhagwati, 1992, 1993). However, theoretical studies on strategic environmental policy suggest that, within the limits of imperfect competition, governments have an incentive to manipulate environmental regulation and utilize environmental policy to promote exports. In an analysis which covers 24 countries and the exports of five pollutionintensive industries: metal mining, nonferrous metals, iron, steel and chemicals, Wilson, Otsuki and Sewadeh (2002) found that countries with less strict environmental regulations on the productions of the products exported relatively more. Furthermore, countries refusing to ratify "Kyoto Protocol" may imply a strategic choice on environmental regulations.

Using the Brander-Spencer framework (1985), Conrad (1993) shows that, given the imperfect competition, if the exports of the targeted polluting industry can earn super-normal returns or rents, its government would deliberately set the emission tax lower than the marginal damage of the pollution so as to shift the rent from its foreign rival. Barrett (1994) reaches a similar conclusion using the emission standard as the surrogate for environmental policy. He concludes that the strategic consideration about the gains accruing from trade leads to an excessive emission standard. The marginal cost of pollution abatement is less than the marginal damage of pollution. Barrett also points out that the desire to obtain more market share drives all of the nations involved in the imperfect competition to relax their environmental standards. In other words, the pressure of the international competition induces a "downward harmonization" of environmental policy across nations. Kennedy (1994) also illustrates the strategic interaction between governments in the imperfect global market and argues that a rent-shift motive causes the distortion on the efficient environmental taxes. The strategic behavior of governments when engaged in designing environmental policy not only influences the stringency level of environmental policy but also affects the choice of policy 
instruments. Ulph (1999) uses a three-stage game showing that, in terms of export promotion, the distorted emission tax is more effective than the distorted emission standard because an optimally distorted emission tax stimulates more exports than does a distorted emission standard. Hence, emission taxes are preferred over emission standards if governments act strategically in their selection of environmental policies. Cassing and Kuhn (2003) analyze how waste importing and exporting countries strategically decide their environmental polices for attaching the rents arising from the trade in an international oligopoly market for waste. They reach a conclusion that the waste exporting country tends to set the waste tax lower than the Pigouvian while the importing country set higher. The strategic behaviors of the two governments contradict to the requirements for a global welfare optimum. Bayindor-Upmann (2003) also argues that, if the pollution is transboundary, governments may set their emission taxes "too low" leading to "ecological dumping." Kayalica and Lahiri (2005) link strategic environmental policies with foreign direct investment and find that FDI host countries may apply lax environmental regulations when foreign firms can enter and exit freely.

These studies provide theoretical justification for the environmentalists' concerns and show that the possibility exists that governments make use of weak environmental standards to enhance the competitiveness of their polluting industries. Because of institutional reasons, not all countries would be able to manipulate their environmental regulation so as to improve their terms of trade. The countries that have to enforce the stringent environmental policy may suffer the loss of market shares in the global competition should their competitors take advantage of the lenient environmental standards. As a result, the governments of these countries may have legitimate reasons to retaliate against their trade partners that pursue strategic environmental policy. Of all the feasible policies, an environmental tariff on the imports of the offending countries might be an optimal choice.

Environmental tariffs have been suggested by both economists and environmentalists (Daly(1994), Arden-Clarke(1993), DeBellevue (1994)) as a mean of preventing the plausible downward harmonization of environmental regulations and eliminating the comparative advantage conferred by lax environmental standards. They argue that lenient environmental policy actually functions as an implicit subsidy that is unfair to countries that internalize all of their environmental costs through strict environmental regulations. The countries with tough environmental regulations should be able to impose environmental tariffs on imports from the lower regulation countries to counterbalance the environmental cost discrepancy. 
The tariffs are essential for high environmental standard countries to maintain competitiveness and protect the efficiency of resource use. The policy prescription of using environmental tariffs to deter distortion of environmental standards has been adopted by some policy makers. For instance, Al Gore states that "just as government subsidies of a particular industry are sometimes considered unfair under the trade laws, weak and ineffectual enforcement of pollution control measures should also be included in the definition of unfair trading practices."(1992). Moreover, environmental tariffs have been a part of proposed legislation. In the "International Pollution Deterrence Act of 1991", countervailing duties against foreign nations whose exports are alleged to have benefited from lenient environmental regulations were introduced. ${ }^{1}$

Several authors have investigated the use of environmental tariffs. Baumol and Oates (1988) show that in the presence of transnational pollution with no collective environmental regulations, zero tariff levels are generally not optimal for the countries importing the commodities which generate the transnational externality. They argue that a tariff can be a second best policy instrument for the circumstance that there exists no other direct policy measure for the transnational pollution. Copeland (1996) also illustrates that pollution content tariffs may be part of the optimal response for the countries suffering the transnational pollution from their trade partners. Ludema and Wooton (1996) analyze the case of the imperfectly competitive market. They conclude that by imposing the environmental tariff, the nation affected by the transnational pollution could not only reduce the externality but also improve their terms of trade. Tanguay (2001) shows that, under international duopolistic competition, banning tariffs will result in a high level of pollution, which in turn undermining the total welfare. While most of studies on strategic environmental polices suggest that the strategic behaviors of government would lead to lax environmental regulations/eco-dumping, Greaker (2003) argues that strict environmental standards could be adopted if the stringent regulation could enhance the competitiveness of domestic firms.

In this paper, we attempt to formulate a theoretical analysis about the effect of environmental tariffs on strategic environmental policy. We focus on whether environmental tariffs could improve the efficiency of resource use and reduce the incentive for governments to pursue strategic environmental policy. To illustrate the rationality of imposing environmental tariffs, we first examine the welfare

${ }^{1}$ U.S. Senate Bill S. 984 (April 25, 1991) 
effect of a country's strategic environmental policy on its rivals. The proponents of environmental tariffs often fail to realize the trade off between the market shares of pollution-intensive products and environmental quality. As a country lowers its environmental policy to improve its terms of trade, the gains of the market shares are at the expense of its domestic environmental quality because more pollution would be generated. Less market shares of pollution-intensive products implies less pollution (better environment). If the benefit of the better environment exceeds the loss of the market share, the argument for environmental tariffs is not justified. Therefore, it is imperative to conduct the welfare analysis proceeding the introduction of environmental tariffs. To outline how environmental tariffs affect the strategic behavior of a country in determining its environmental policy, we use a three-stage game. The framework of the analysis is the model of international duopoly with negative externality in production.

Our studies differ with the current literature. First, in the context of the conventional literature, environmental tariffs are used as an instrument to reduce transnational externality. This paper excludes the possibility of transnational pollution. The production externality in our model is depletable and cannot spillover the border. The environmental tariff in our analysis is designed as a mean of countervailing measures for the rent-shift motive of the foreign country through the lenient environmental regulation. Second, the welfare of the home country consists of consumer surplus, producer surplus, the detrimental externality, and the emission fee. It is more comprehensive and general than the welfare defined in the other literature (such as, Conrad , 1993; Ludema and Woonton, 1996). The generalized welfare definition enables us to consider the trade-off between a better environment (less pollution) and a lower market share. We find that the strategic environmental policy would not necessarily undermine the welfare of the home country. There exists the possibility that the losses of the market share would be offset by the reduction of the pollution due to a lower market share of the domestic industry. In this circumstance, there is no need to impose the environmental tariff on the pollutionintensive imports. Finally, unlike other literature that only considers unilateral environmental regulations, we consider a scenario in which the environmental regulations prevail in both the home and foreign countries. Only the stringency of the regulations differs. As a consequence, we can investigate how the implementation of environmental tariff affects the choices of the environmental policies of both the home and foreign countries. We show that, without the environmental tariff both countries would lower their environmental standards. On the other hand, 
the environmental tariff would induce the upward harmonization of the environmental standards between the two countries. That is the two countries would readjust their environmental regulations toward the optimal level if the home country imposes the optimal environmental tariff as a countervailing measure for the strategic environmental policy of the foreign country.

\section{An International Duopoly Model with Environmental Regulation}

Consider a hypothetical open economy with two countries: a home country and a foreign country. Each country has only one firm and both firms produce homogenous product $x$, which is pollution intensive. The production technology is identical across countries and is denoted by cost function $C(x)$, which is a convex function with twice continuous differential. Unlike other literature, we postulate that the two firms conduct Cournot competition in the home country, rather than in the third country. The foreign firm exports all of its output to the home country. Total market supply $Q$ of the home country is equal to the output of the domestic firm and the foreign exports. We use the inverse demand function $P(Q)$ to describe the home country's demand and $P^{\prime}(Q)<0$.

In association with the production of goods $x$, pollutant $E$ is emitted. The emissions function is $\gamma(x)$, which is an increasing function of output $x$, i.e., $\mathrm{r}^{\prime}>0$. The pollution is depletable and cannot spill over the boundary; therefore, there is no transnational pollution in the model. As regards pollution reduction, both domestic and foreign firms install identical abatement technology, which is denoted by cost function $A(a)$, a convex function with twice continuous differential. To regulate pollution, the two countries' governments charge emission taxes $e^{i}$ on their firms respectively, where $\mathrm{i}=\mathrm{H}$ or $\mathrm{F}$ (Home or Foreign). The foreign government may incorporate the strategic consideration into its environmental policy and manipulate its environmental policy to gain more market share. To counter the strategic move of the foreign country, the home country levies an environmentally oriented tariff, $t$, on the imports.

This model structure is very similar to the competition between the U.S domestic industries and the manufacturers in Maquiladora region of Mexico. Most manufacturers in Maquiladora export zone target the U.S market. They export all of their products to the U.S market. Mexican environmental regulations are either lenient compared to U.S standards or there exists no effective enforcement. On the other 
hand, the U.S domestic manufacturers are subject to higher domestic environmental standards that impose substantial pollution abatement and control costs. To reduce the gap between the two countries' environmental standards, the U.S. currently charges border taxes on some chemical products imported from Mexico. This border charge is a type of environmental tariff.

For any given emission tax $e^{i}$ and tariff $t$, profits $\pi$ of both domestic and foreign firms are represented by the following functions:

$$
\begin{gathered}
\pi^{H}=P(Q) x-C(x)-e^{H}\left[\gamma(x)-a^{H}\right]-A\left(a^{H}\right) \\
\pi^{F}=P(Q) y-C(y)-e^{F}\left[\gamma(y)-a^{F}\right]-A\left(a^{H}\right)-t y .
\end{gathered}
$$

where $x$ and $y$ are the outputs of the domestic and foreign producers respectively, $a^{i}$ denotes the abatement levels chosen by the firms, and $\left(\gamma(x)-a^{H}\right)$ and $\left(\gamma(y)-a^{F}\right)$ indicate the net emissions in the two countries. To analyze the firms' reaction to the policy parameters, we introduce two standard assumptions about the profit functions: (1) $\pi_{x x}<0$ and $\pi_{y y}<0$; and (2) $\pi_{x y}$ or $\pi_{y x}<0$. The first assumption states that the marginal profits of both producers are decreasing; the second implies that if one producer's output increases, the marginal profits of the other will decline.

Next, we define the two countries' welfare. The home country's welfare, $W^{H}$, is defined as the sum of consumers' surplus, producer's surplus, tax revenues, and the detrimental externality caused by pollution. The detrimental externality is represented by damage function $D($.$) , which is a convex function of the emissions$ and has twice continuous differentials. The home country's welfare is

$$
W^{H}=\int_{0}^{Q} P(q) d q-P Q+\pi^{H}+t y+e^{H}\left[\gamma(x)-a^{H}\right]-D\left[\gamma(x)-a^{H}\right],
$$

where $D\left(\gamma(x)-a^{H}\right)$ represents the total damage or the negative utility borne by the home country. Since the home country government is an agent in the model, tariff ty and total emission charge, $e^{H}\left(\gamma(x)-a^{H}\right)$ are included in (3) as part of the nation's welfare. Similarly, the welfare of the foreign country, $W^{F}$, is specified as:

$$
W^{F}=\pi^{F}+e^{F}\left[\gamma(y)-a^{F}\right]-D\left[\gamma(y)-a^{F}\right]
$$

The discussion starts with the optimal decisions of the two producers under given emission tax $e^{i}$ and tariff $t$. The domestic firm will maximize its profit $\pi^{H}$ to 
decide its optimal output $\mathrm{x}$ and abatement level $a^{H}$. Differentiating the profit function of the domestic firm, $\pi^{H}$, with respect to $x$ and $a^{H}$, yield the first order conditions (FOC) of the domestic firm profit maximization:

$$
\begin{gathered}
P+x P^{\prime}-C_{x}-e^{H} \gamma_{x}=0 \\
e^{H}-A^{\prime}\left(a^{H}\right)=0
\end{gathered}
$$

FOC (5.2) is simply the familiar proposition that the firm will abate pollution to the point at which the marginal abatement cost is equal to emission tax $e^{H}$. In the same fashion, the FOC of the foreign firm's profit maximization is derived as follows:

$$
\begin{gathered}
P+y P^{\prime}-C_{y}-e^{F} \gamma_{y}-t=0 \\
e^{F}-A^{\prime}\left(a^{F}\right)=0
\end{gathered}
$$

Thus, for any given policy vector $\left(e^{H}, e^{F}, t\right)$, FOC (5.1), (5.2), (6.1), and (6.2) jointly determine unique Nash equilibrium outputs $x\left(e^{H}, e^{F}, t\right)$ and $y\left(e^{H}, e^{F}, t\right)$. (5.2) and (6.2) implicitly define the abatement levels, $a^{i}$, chosen by the two firms at the equilibrium.

\section{The Marginal Effect of Emission Taxes on Market Share}

To derive the marginal effects of emission tax $e^{i}$ and tariff $t$ on the NashEquilibrium output, $x\left(e^{H}, e^{F}, t\right)$ and $y\left(e^{H}, e^{F}, t\right)$, we totally differentiate (5.1) and (6.1). It yields

$$
\left|\begin{array}{cc}
2 P^{\prime}+x P^{\prime \prime}-C_{x x}-e^{H} \gamma_{x x} & P^{\prime \prime}+p^{\prime} \\
P^{\prime \prime}+p^{\prime} & 2 P^{\prime}+y P^{\prime \prime}-C_{y y}-e^{F} \gamma_{y y}
\end{array}\right| \begin{gathered}
d x \\
d y
\end{gathered}|=| \begin{gathered}
\gamma_{x} d e^{H} \\
d t+\gamma_{y} d e^{F}
\end{gathered} \mid
$$

To simplify the discussion that follows, we use $\Pi$ to denote the determinant of the Hessian matrix above, i.e. 


$$
\Pi=\left|\begin{array}{cc}
2 P^{\prime}+x P^{\prime \prime}-C_{x x}-e^{H} \gamma_{x x} & P^{\prime \prime}+p^{\prime} \\
P^{\prime \prime}+p^{\prime} & 2 P^{\prime}+y P^{\prime \prime}-C_{y y}-e^{F} \gamma_{y y}
\end{array}\right|
$$

The existence of the local maximization of the firms' profit functions requires that the determinant of the Hessian matrix be positive, i.e., $\Pi>0$. Using Cramer's rule, and the assumptions about emissions function $\gamma\left(\right.$.) and profit functions $\pi^{i}$, we deduce the following comparative static effects of emission taxes $e^{i}$ :

$$
\begin{aligned}
& \frac{d x}{d e^{H}}=\frac{\gamma_{x} \pi_{y y}^{F}}{\Pi}<0 \\
& \frac{d y}{d e^{H}}=\frac{-\pi_{y x}^{F} \gamma_{x}}{\Pi}>0 \\
& \frac{d x}{d e^{F}}=\frac{-\gamma_{y} \pi_{x y}^{H}}{\Pi}>0 \\
& \frac{d y}{d e^{F}}=\frac{\gamma_{y} \pi_{x y}^{H}}{\Pi}<0
\end{aligned}
$$

These comparative static results are equivalent to those derived by Conrad(1992). They suggest that a country's emission tax would have a negative relationship with its producer's output but a positive association with its rival's output. The explanation is that emission taxes are utilized to internalize environmental costs for the firms. If a country raises its emission tax, the marginal cost of its firm will rise correspondingly and the increased marginal production costs will depress the firm's output. In the duoply model, the contraction of one producer will trigger the expansion of the other.

Similarly, we derive the marginal effects of tariff $\mathrm{t}$ on the Nash-Equilibrium outputs, $x\left(e^{H}, e^{F}, t\right)$ and $y\left(e^{H}, e^{F}, t\right)$ :

$$
\begin{aligned}
& \frac{d x}{d t}=\frac{\pi_{x y}}{\Pi}>0 \\
& \frac{d y}{d t}=\frac{\pi_{x x}^{H}}{\Pi}<0 .
\end{aligned}
$$

In contrast to emission taxes, the tariff will aid the domestic producer in gaining more market share and discourage the foreign firm's production. If the home 
country levies the environmentally oriented tariff on the pollution intensive imports from the foreign country, the tariff will extract part of the rent earned by the foreign producer. As a result, the realized profit of the foreign producer is lower than expected and the foreign producer reduces its output accordingly. The reduction of the foreign imports would be offset by an increase of the home firm's production and a decrease in the consumption. We will utilize the comparative static results in the discussions of the next two sections.

\section{Strategic Environmental Policy and Its Welfare Effect}

Finding the benchmark for examining the effectiveness of environmental tariffs requires first considering the circumstance that the home government imposes no tariff on imports from the foreign country. In this part, we will derive the optimal emission taxes of both countries and the welfare impact of the foreign country's environmental policy on the home country without considering tariffs.

As regards the foreign government, its strategic behavior depends on whether lowering its emission tax $e^{F}$ from the first best level would improve its welfare $W^{F}$. To illustrate this point, it is necessary to evaluate the $\partial W^{F} / \partial e^{F}$ at $e^{F}=D^{\prime}$. Taking the differential of $W^{F}$ with respect to $e^{F}$ and applying FOC (6.1) and (6.2) derives

$$
\frac{\partial W^{F}}{\partial e^{F}}=P^{\prime} y\left(\frac{\partial x}{\partial e^{F}}\right)+\left[e^{F}-D^{\prime}\right]\left[\gamma_{y}\left(\frac{\partial y}{\partial e^{F}}\right)-\frac{\partial a^{F}}{\partial e^{F}}\right]
$$

Equation (9) indicates the overall welfare effect of $e^{F}=D^{\prime}$ on the foreign country. Substituting $e^{F}=D^{\prime}$ into (9), $\partial W^{F} / \partial e^{F}$ becomes

$$
\frac{\partial W^{F}}{\partial e^{F}}=P^{\prime} y\left(\frac{\partial x}{\partial e^{F}}\right)
$$

Since $P^{\prime}<0$ and $\partial x / \partial e^{F}>0$, the partial derivative $\partial W^{F} / \partial e^{F}$ at $e^{F}=D^{\prime}$ is negative. The negative sign suggests that the emission tax, defined by $e^{F}=D^{\prime}$, is not an optimal choice for the foreign country, and any deduction from it will improve the welfare of the foreign country. Since the objective of the foreign government is to maximize its welfare, $W^{F}$, it will reduce its emission tax, $e^{F}$, until $\partial W^{F} / \partial e^{F}$ equals to zero. Setting (9) equal to zero yields 


$$
e^{F}=D^{\prime}-\left(P^{\prime} y \frac{\partial x}{\partial e^{F}}\right)\left[\gamma_{y} \frac{\partial y}{\partial e^{F}}-\frac{\partial a^{F}}{\partial e^{F}}\right]^{-1} .
$$

The emission tax $e^{F}$ defined by (11) is the strategic emission tax employed by the foreign country under the regime without countervailing measures. Since $P^{\prime}<0$, $\partial x / \partial e^{F}>0, \gamma^{\prime}(y)>0, \partial y / \partial e^{F}<0$, and $\partial a / \partial e^{F}>0$, the second term in (11) is positive, i.e.,

$$
\left(P^{\prime} \frac{\partial x}{\partial e^{F}}\right)\left[\gamma_{y} \frac{\partial y}{\partial e^{F}}-\frac{\partial a^{F}}{\partial e^{F}}\right]^{-1}>0
$$

This implies that the strategic emission tax chosen by the foreign country is less than the marginal damage of pollution.

The desire to acquire more market share may also motivate the home country to lower its emission tax in competing with the foreign country without imposing tariffs on foreign imports. This can be illustrated by the discussion below about the optimal environmental tax of the home country. Differentiating $W^{H}$ with respect to $e^{H}$ gives

$$
\frac{\partial W^{H}}{\partial e^{H}}=-Q \frac{\partial P}{\partial e^{H}}+x P^{\prime} \frac{\partial y}{\partial e^{H}}+\left[e^{H}-D^{\prime}\right]\left[\gamma_{x} \frac{\partial x}{\partial e^{H}}-\frac{\partial a^{H}}{\partial e^{H}}\right]
$$

Let $\partial W^{H} / \partial e^{H}=0$, then

$$
e^{H}=D^{\prime}+\left[Q \frac{\partial P}{\partial e^{H}}-x P^{\prime} \frac{\partial y}{\partial e^{H}}\right]\left[\gamma_{x} \frac{\partial x}{\partial e^{H}}-\frac{\partial a^{H}}{\partial e^{H}}\right]^{-1}
$$

Since $\left(Q\left(\partial P / \partial e^{H}\right)-x P^{\prime}\left(\partial y / \partial e^{H}\right)\right)>0$ and $\left(\gamma_{x}\left(\partial x / \partial e^{H}\right)-\left(\partial a / \partial e^{H}\right)\right)<0$, the optimal emission tax of the home country is also less than the marginal damage $D^{\prime}$. There are two reasons for the lower emission tax. One is the market power. Pigouvian tax normally reduces the outputs of the firm to below its previous level. However, in this duoply model, the firm has already restricted its output to below its optimal level, and the additional contraction of output induced by the tax, will affect the welfare negatively. This negative effect is represented by $Q\left(\partial P / \partial e^{H}\right)$, i.e. the loss of the consumer surplus. The other is competition. As shown in section III, the emission tax has a negative association with domestic market share but a positive association with its rival. The high emission tax will inevitably undermine its firm's competitiveness and result in less market share, which is detrimental to the home 
country's welfare. Such an effect is indicated by $-x P^{\prime}\left(\partial y / \partial e^{H}\right)$. The discussion above reveals that, without trade instruments, both countries may lower their environmental standards and deviate from the first best policy. The only incentive for the foreign country to lower its emission tax is to gain more market share.

We will now turn to a discussion of the welfare effect of the foreign country's emission tax $e^{F}$ on the home country. Differentiating $W^{H}$ with respect to $e^{F}$ and using FOC (5.1) and (5.2) yields

$$
\frac{\partial W^{H}}{\partial e^{F}}=-Q\left(\frac{\partial P}{\partial e^{F}}\right)+x P^{\prime}\left(\frac{\partial y}{\partial e^{F}}\right)+t\left(\frac{\partial y}{\partial e^{F}}\right)+\left(e^{H}-D^{\prime}\right) \gamma_{x} \frac{\partial x}{\partial e^{F}} .
$$

In (13), the overall welfare impact is decomposed into four terms. The first term is the consumer surplus effect. With some manipulation, the consumer surplus effect can be expressed as:

$$
-Q \frac{\partial P}{\partial e^{F}}=P^{\prime}\left(\frac{\partial x}{\partial y}+1\right) \frac{\partial y}{\partial e^{F}} .
$$

The uniqueness of Nash-Equilibrium requires $(\partial x / \partial y+1)>0$. So, the consumer surplus effect is negative. The simple explanation for the negative consumer surplus effect is that the high emission tax of the foreign country will drive up the market price, which reduces the consumer surplus. The second term is the rentshift effect. This effect is positive due to $P^{\prime}>0$ and $\partial y / \partial e^{F}<0$. The third term simply signifies the effect of emission tax $e^{F}$ on the tariff revenue. Since the foreign firm will cut its exports whenever emission tax $e^{F}$ goes up, the effect of the tariff revenue is negative. The last term is the externality effect. Because tax $e^{H}<D^{\prime}$ and $\partial x / \partial e^{F}>0$, the externality effect is negative. This can be explained as follows. As foreign emission tax $e^{F}$ rises, the domestic firm is able to take advantage of the higher foreign emission tax and will produce more. The pollution emission of the home country also increases as the result of the increased production. Therefore, the externality effect is negative.

Substituting $t=0$ into (13) yields

$$
\frac{\partial W^{H}}{\partial e^{F}}=-Q\left(\frac{\partial P}{\partial e^{F}}\right)+x P^{\prime}\left(\frac{\partial y}{\partial e^{F}}\right)+\left(e^{H}-D^{\prime}\right) \gamma_{x} \frac{\partial x}{\partial e^{F}} .
$$

(15) represents the welfare effect when the home government levies zero tariff on the foreign imports. The welfare effect includes three components: the rent-shift effect, the consumer surplus effect and the externality effect. As illustrated above, 
the consumer surplus effect and the externality effect are negative but the rent-shift effect is positive. Hence, the welfare impact of the lenient emission tax of the foreign country is ambiguous. This implies that, under some circumstances, it is not optimal to impose countervailing tariffs on foreign imports, and lenient foreign environmental policy may cause the home country to be better off because the home country benefits from less pollution as well as relatively more market supply. In other literature about strategic environmental policy, the effect of environmental policy on consumer surplus and detrimental externality are ignored. On the other hand, should the rent-shift effect predominate over the gains from the consumer surplus and less pollution, i.e.

$$
-Q\left(\frac{\partial P}{\partial e^{F}}\right)+x P^{\prime}\left(\frac{\partial y}{\partial e^{F}}\right)+\left(e^{H}-D^{\prime}\right) \gamma_{x} \frac{\partial x}{\partial e^{F}}>0
$$

Then, the welfare effect will be negative. That is, the home country will be worse off as the foreign country relaxes its emission tax $e^{F}$. Using the comparative results derived in section III, inequality (16) can be written as:

$$
-p^{\prime} y \gamma_{y}\left(\frac{\pi_{x x}-\pi_{x y}}{\Pi}\right)+P^{\prime} x \gamma_{y} \frac{\pi_{x y}}{\Pi}-\left(e^{H}-D^{\prime}\right) \gamma_{x} \gamma_{y} \frac{\pi_{x y}}{\Pi}>0
$$

The findings in this section are summarized below.

Proposition 1: In a world of imperfect competition, both the home and foreign countries have incentives to lower their emission taxes. The welfare effect of the lenient environmental policy on the home country is ambiguous. If condition (17) holds, the home country will become worse off as the foreign country relaxes its emission tax.

\section{The Optimal Environmental Tariff}

The effect of environmental tariffs on strategic environmental policy will now be considered. In this section, the home country charges an import tariff in response to the foreign lenient emission tax, which exerts an adverse impact on the home country's welfare. The discussion is modeled as a three-stage game. During the first stage of the game, the foreign government decides on its strategic environmental policy prior to the home country's decision making. During the second stage, the 
home government takes the foreign emission tax $e^{F}$ as given and selects its optimal environmental tariff $\mathrm{t}$ and its emission tax $e^{H}$. During the last stage, both domestic and foreign firms determine their outputs with regard to the announced emission taxes $e^{i}$ and tariff $t$ in the first two stages. We employ backward induction to deduce the subgame equilibria of this three-stage game.

\section{Stage-Three}

During the last stage, both domestic and foreign firms must make two decisions simultaneously. The first decision concerns their optimal outputs; the second, their optimal pollution abatement levels. Section II presented in detail how the two firms choose their optimal outputs and abatement levels under policy parameters $e^{i}$ and $t$. The results lead to the conclusion that the subgame equilibrium of the last stage is implicitly characterized by FOCs (5.1), (5.2), (6.1) and (6.2).

\section{Stage-Two}

During the second stage, the home country's government determines the optimal environmental tariff $t$ and readjusts its optimal emission tax $e^{H}$ by maximizing its welfare. Differentiating $W^{H}$ with respect to $t$ and applying the first order conditions of the domestic firm's profit maximization, (5.1) and (5.2) derives the FOC for the optimal tariff:

$$
\frac{\partial W^{H}}{\partial t}=-Q\left(\frac{\partial P}{\partial t}\right)+x P^{\prime}\left(\frac{\partial y}{\partial t}\right)+\gamma_{x}\left(\frac{\partial x}{\partial t}\right)\left(e^{H}-D^{\prime}\right)+y+t\left(\frac{\partial y}{\partial t}\right)=0 .
$$

Thus, the solution of optimal environmental tariff $t$ is

$$
t=-y\left(\frac{\partial y}{\partial t}\right)^{-1}-\left[Q\left(\frac{\partial P}{\partial t}\right)-x P^{\prime}\left(\frac{\partial y}{\partial t}\right)\right]\left(\frac{\partial y}{\partial t}\right)^{-1}-\gamma_{x}\left(\frac{\partial x}{\partial t}\right)\left(e^{H}-D^{\prime}\right)\left(\frac{\partial y}{\partial t}\right)^{-1} .
$$

Applying the comparative static results derived in section II, the optimal tariff can be written as:

$$
t=-y\left(\frac{\pi_{x x}}{\Pi}\right)^{-1}+\left[\left(p^{\prime} y \frac{\left(\pi_{x x}-\pi_{x y}\right)}{\Pi}-P^{\prime} x \frac{\pi_{x y}}{\Pi}+\left(e^{H}-D^{\prime}\right) \gamma_{x} \frac{\pi_{x y}}{\Pi}\right)\left(\frac{\pi_{x x}}{\Pi}\right)^{-1}\right] .
$$

Since $\pi_{x x}<0$ and $\Pi>0$, the first term $-y\left(\pi_{x x} / \Pi\right)^{-1}$ on the right side of (20) is positive. If condition (14) holds, it is straightforward to prove that the second term, bounded by the square brackets, is also positive. Inequality (17) is the sufficient and necessary condition under which welfare $W^{H}$ will be adversely affected by the lenient emission tax of the foreign country. We conjecture that the home country 
will implement the countervailing measures if, and only if, the lax environmental policy of the foreign country impairs the home country's welfare. Therefore, the optimal environmental tariff defined by (20) is positive. This demonstrates that the home country will choose tariffs over subsidies as instruments for eliminating the disadvantage caused by the lenient environmental policy of the foreign country.

As the home country imposes tariffs on the foreign imports, the optimal emission tax, $\mathrm{e}^{\mathrm{H}}$, should be determined by the FOC below:

$$
\frac{\partial W^{H}}{\partial e^{H}}=-Q\left(\frac{\partial P}{\partial e^{H}}\right)+x P^{\prime}\left(\frac{\partial P}{\partial e^{H}}\right)+\left(e^{H}-D^{\prime}\right)\left[\gamma_{x}\left(\frac{\partial x}{\partial e^{H}}\right)-\frac{\partial a^{H}}{\partial e^{H}}\right]+t\left(\frac{\partial y}{\partial e^{H}}\right)=0 .
$$

Thus, the optimal emission tax under the regime with the countervailing tariff is

$$
e^{H}=D^{\prime}+\left[Q\left(\frac{\partial P}{\partial e^{H}}\right)-x P^{\prime}\left(\frac{\partial y}{\partial e^{H}}\right)-t\left(\frac{\partial y}{\partial e^{H}}\right)\right]\left[\gamma_{x}\left(\frac{\partial x}{\partial e^{H}}\right)-\frac{\partial a^{H}}{\partial e^{H}}\right]^{-1} .
$$

Since $t\left(\partial y / \partial e^{H}\right)>0$, the optimal emission tax defined by (22) is higher than the emission tax under circumstances where the home country imposes no countervailing tariffs on foreign imports. In other words, the home country will align its emission tax to the first best level. Hence, with the enforcement of the optimal tariff, the incentive for the home country to relax its emission tax is reduced. Rather than lower its emission tax, the home country will raise the emission tax by $t\left(\partial y / \partial e^{H}\right)$. Therefore, the environmental cost will be internalized and efficiency of resources will be improved through use of the optimal tariff.

The optimal environmental tariff is supposed to correct the distortion of the home country's welfare $W^{H}$. Now we will examine whether the objective will be achieved. Differentiating $W^{H}$ with respect to $e^{F}$ and using FOC (5.1) and (5.2) yields

$$
\begin{aligned}
\frac{\partial W^{H}}{\partial e^{H}}=- & Q\left(\frac{\partial P}{\partial e^{F}}\right)+P^{\prime} x\left(\frac{\partial y}{\partial e^{F}}\right)+\left(e^{H}-D^{\prime}\right)\left[\gamma_{x}\left(\frac{\partial x}{\partial e^{F}}\right)-\frac{\partial a^{H}}{\partial e^{F}}\right] \\
& +\left(\frac{\partial e^{H}}{\partial e^{F}}\right)\left[\gamma(x)-a^{H}\right]+t\left(\frac{\partial y}{\partial e^{F}}\right)+y\left(\frac{\partial t}{\partial e^{F}}\right)
\end{aligned}
$$

Using FOC (18) for the optimal environmental tariff $t$ together with FOC (21) for the optimal emission tax, the above expression can be simplified to 


$$
\frac{\partial W^{H}}{\partial e^{H}}=-y\left(\frac{\partial y}{\partial e^{F}}\right)\left(\frac{\partial y}{\partial t}\right)^{-1}+\left[\gamma(x)-a^{H}\right]\left(\frac{\partial x}{\partial e^{F}}\right)\left(\frac{\partial x}{\partial e^{H}}\right)^{-1} .
$$

The derivative $\partial W^{H} / \partial e^{F}$ defined in (24) reflects the welfare effect of emission tax $e^{F}$ when the home country not only imposes the optimal environmental tariff on the imports of the foreign country but also increases the emission tax. Because $\partial y /$ $\partial e^{F}<0$ and $\partial y / \partial t<0$,

$$
\frac{\partial W^{H}}{\partial e^{F}}<0
$$

Inequality (25) unequivocally suggests that there exists a negative association between welfare $\mathrm{W}^{\mathrm{H}}$ and emission tax $e^{F}$. If the foreign country relaxes its emission $\operatorname{tax} e^{F}$, the welfare of the home country will increase. In contrast to the inferences under the regime without the countervailing measure, the optimal tariff effectively eliminates the negative welfare impact caused by the strategic behavior of the foreign country. Consequently, without deducting its emission tax $e^{H}$ from the efficient level, the home country will be better off imposing the optimal tariff on by the imports from the foreign country if the latter attempts to implement a strategic environmental policy. These findings are summarized as

Proposition 2: If the home country imposes the optimal environmental tariff on the imports of the foreign country, it will readjust its environmental policy toward the first best level and benefit from the strategic environmental policy of the foreign country.

\section{Stage-One}

During the first stage, the foreign country chooses its strategic emission tax $e^{F}$ by maximizing welfare $W^{F}$. In this three-stage game, the foreign country anticipates that the home country will use tariffs to retaliate its strategic behavior in designing its environmental policy. Therefore, when maximizing its welfare, $W^{F}$, the foreign government will take into consideration the home country's reaction by treating tariff $\mathrm{t}$ as a function of its emission tax, $e^{F}$. Maximizing $W^{F}$ with respect to $e^{F}$ and using FOCs (6.1) and (6.2) yield

$$
\frac{\partial W^{H}}{\partial e^{H}}=P^{\prime} y \frac{\partial x}{\partial e^{F}}-y \frac{\partial t}{\partial e^{F}}+\left(e^{F}-D^{\prime}\right)\left(\gamma_{y} \frac{\partial y}{\partial e^{F}}-\frac{\partial a^{F}}{\partial e^{F}}\right) .
$$

Setting (26) equal to zero, the strategic emission tax $e^{F}$ under the regime with 
environmental tariff $t$ is

$$
e^{F}=D^{\prime}-\left(P^{\prime} y \frac{\partial x}{\partial e^{F}}-y \frac{\partial t}{\partial e^{F}}\right)\left[\gamma_{y} \frac{\partial y}{\partial e^{F}}-\frac{\partial a^{F}}{\partial e^{F}}\right]^{-1}
$$

Comparing (27) and (11) shows that emission tax $e^{F}$ defined by (27) is higher than the one defined by (11), the social optimum without import tariffs, because

$$
y\left(\frac{\partial t}{\partial e^{F}}\right)=-y\left(\frac{\partial t}{\partial e^{F}}\right)\left(\frac{\partial y}{\partial t}\right)^{-1}<0 .
$$

The discrepancy between the two strategic emission taxes suggests that the deduction of the strategic emission tax from the first best level is less than in the regime without countervailing tariffs. Consequently, the implementation of the optimal tariff effectively drives the foreign government back to the first best environmental policy and thus reinstates the efficient usage of environmental resources. The reason for this is given below. As the foreign country relaxes its emission tax, both the outputs and the pollution emissions of its firm will rise simultaneously. Without the tariff, the rent earned by its firm can offset the aggravated environmental damage. However, once the home country imposes the tariff on the imports, part of the rent will be transferred to the home country while the total increased pollution is still borne by the foreign country. As a result, the expected gains from the strategic environmental policy will diminish and the foreign government will adjust its emission tax, $e^{F}$. This section can be summarized as

Proposition 3: The optimal tariff can mitigate the motivation of the foreign country to deviate from the first best environmental policy and thus reinstate the efficiency of resource use.

The underlying implication of Proposition 3 is that using the optimal tariff will induce the upward harmonization of environmental policy between the two countries. In the arguments for using environmental tariffs, they are usually considered to be countervailing measures or punitive mechanisms. Their potential effect on the foreign environmental policy is often overlooked. we consider the upward harmonization phenomenon to be more important in the sense of maintaining sustainable development, globally. 


\section{Conclusion}

Recent studies on the strategic environmental policy indicate that environmental policy might be employed as new instrument to improve the terms of trade in the imperfect global market. The authors predict that, if all countries competing in the market behave strategically, the rent-shift motive would distort the efficient environmental policy and result in the downward harmonization of the environmental standards across nations. Because of institutional reasons, not all governments can manipulate their environmental policy so as to promote exports. The welfare of the nations that enforce stringent environmental standards may be adversely affected by the strategic environmental policy of their rivals. Hence, the governments of these nations may retaliate against the countries pursuing strategic environmental policy by imposing environmental tariffs on the imports. This paper uses a simple international duopoly model to simulate the scenario. It presents a theoretical study about the welfare impact of the strategic environmental policy on its rivals and analyzes the impact of the environmental tariff on strategic behavior. With the more comprehensive definition of welfare, we find that the welfare impact is ambiguous. The strategic environmental policy of the foreign country may not necessarily undermine the welfare of the home country that enforces stringent environmental standards. The rational is that the gains of the foreign country are at the cost of its environmental deterioration. The home country's rent losses could be offset by better environmental quality. As long as the increased pollution generated by the production process of the imports is depletable or does not have transnational effect, it is possible that the strategic behavior of the foreign government would benefit the home country. In this circumstance, there is no need to impose the environmental tariff to countervail the strategic move of the foreign country. The substantial policy implication is that the argument for environmental tariffs should be based on the rigorous welfare analysis rather than the losses or the gains of polluting industry.

In the circumstance that the home country is worse off because of the strategic behavior of the foreign government, there exists an optimal environmental tariff. Through a three-stage game, we show that a well defined tariff could effectively remedy the welfare distortion caused by the strategic policy of the foreign country. Moreover, the optimal tariff could serve as an effective deterrent to the strategic behavior of the foreign country and indirectly reinstate the efficient environmental policy in the foreign country. With the implementation of the optimal environ- 
mental tariff, both countries raise their emission taxes toward the first best level. In other words, the environmental tariff induces an upward harmonization of the environmental standards between the two countries.

Using trade instruments such as tariffs to address the environment-competitiveness issue is one focal point in the debate over trade and the environment. Free trade proponents have objected to the idea. They criticize the proposal as a new form of protectionism and warn that implementation of the tariff will cause new distortions and undermine the world trade system (Bhagwati,1992, 1993). However, in the case of strategic environmental policy, the laxity of the environmental policy is the result of the desire for more market share rather than innocent reasons such as an abundant endowment of assimilative capacity. The strategic environmental policy actually functions as an export promotion strategy. Moreover, as indicated by Proposition 1, the gains from the strategic environmental policy come at the expense of its rivals. Therefore, the environmental tariff is justified in the noncooperative environment, or, at least can be used as a threat to prevent the strategic behavior of governments under the imperfect competition.

\section{Appendix}

During the second stage, optimal tariff $\mathrm{t}$ and emission tax $\mathrm{e}^{\mathrm{H}}$ can be derived by solving FOCs (18) and (21). The exact expression for the optimal tariff, $t$, is

$$
\begin{aligned}
& t=\left\{-y\left(\frac{\pi_{x x}}{\Pi}\right)^{-1}+P^{\prime} y\left(1-\frac{\pi_{x y}}{\pi_{x x}}\right)-P^{\prime} x \frac{\pi_{x y}}{\pi_{x x}}+\left[P^{\prime} y\left(\pi_{y y}-\pi_{x y}\right)+P^{\prime} x \pi_{y y}\right]\right. \\
& \left.\quad\left(\pi_{y y}-\Pi A^{\prime \prime} \gamma_{x}^{-2}\right)^{-1}\right\}\left[1-\frac{\gamma_{x} \pi_{x y}}{\Pi}\left(\frac{\gamma_{x}^{2} \pi_{y y}}{\Pi}-A^{\prime \prime}\right)^{-1}\right]^{-1}
\end{aligned}
$$

Substituting the expression above into (22), we can obtain the explicit solution for $\mathrm{e}^{\mathrm{H}}$.

Received 8 October 2004, Accepted 11 July 2006

\section{References}

Arden-Clarke, C.(1994), "Environment, Competitiveness and Countervailing Measure," in Environmental Policy and Industrial Competitiveness, OECD, Paris.

Bhagwati, J. (1993), "The Case for Free Trade," Scientific American, November: 42-49. 
Bhagwati, J.(1992), "Trade and the Environment," The American Enterprise.

Barrette, S. (1994) "Strategic Environmental Policy and International Trade," Journal of Public Economics, 54:325-338.

Baumol, W.J. and W.E. Oates (1988), The Theory of Environmental Policy, Cambridge: Cambridge University Press.

Bayindir_Upmann, T. (2003), "Strategic Environmental Policy under Free Entry of Firms," Review of International Economics, 11(2):379-96.

Brander, J.A. and B.J. Spencer (1985) "Export Subsidies and International Market Share Rivalry," Journal of International Economics, 18:83-100.

Cassing, J. and Kuhn, T. (2003), "Strategic Environmental Policies When Waste Products are Tradable," Review of International Economics, 11(3):495-511.

Conrad, K. (1993), "Taxes and Subsidies for Pollution-Intensive Industries as Trade Policy," Journal of Environmental Economics and Management, 25:121-35.

Copeland, B. R. (1996) "Pollution Content Tariffs, Environmental Rent Shifting, and the Control of Cross-border Pollution," Journal of International Economics, 40:459-76.

Daly, H. (1993), "The Perils of Free Trade," Scientific American, November: 50-57.

Debellevue, E. et al, (1994), "The North American Free Agreement: an Ecological-Economic Synthesis for the United States and Mexico," Ecological Economics, 9: 53-71.

Greaker, M. (2003), "Strategic Environmental Policy: Eco-Dumping or Green Strategy?" Journal of Environmental Economics and Management, 45(3): 692-707.

Gore, A (1992), Earth in the Balance: Ecology and the Human Spirit. Houghton Mifflin, New York.

Fudenberg, D. and J. Tirole (1991), Game Theory, Cambridge: The MIT Press.

Low, P. 1992. "Trade Measure and Environmental Quality: The Implication for Mexico' Exports," in P. Low (ed.) International Trade and the Environment, World Bank Discussion Papers, No. 159.

Kayalica, M. O. and Lahiri, S. (2005), "Strategic Environmental Policies in the Present of Foreign Direct Investment," Environmental and Resource Economics, 30(1): 1-21.

Kennedy, P. W. (1994) "Equilibrium Pollution Taxes in Open Economies with Imperfect Competition," Journal of Environmental Economics and Management, 27:49-63.

Ludema, R. D. and I. Wooton (1994) "Cross-border Externalities and Trade Liberalization: the Strategic Control of Pollution," Canadian Journal of Economics, XXVII(4), 951-66.

Steininger, K. (1994), "Reconciling Trade and Environment: Towards a Competitive Advantage for Long-Term Policy Goods," Ecological Economics, 9:23-42.

Tanguay, G.A. (2001), "Strategic Environmental Policies under International Duopolistic Competition," International Tax and Public Finance, 8(5-6): 793-811.

Ulph, A. (1999), "International Environmental Regulation when National Governments Act Strategically," in Trade and the Environment: Selected Essays of Alistair M, Chelterham, U.K.: Elgar.

Wilson, J.S., Otsuki, T. and Sewadeh, (2002), "Dirty Exports and Environmental Regulations: Do Standards Matters to Trade?", Development Research Group, the World Bank. 